\title{
O Circuito do Capital-Industrial e a Dinâmica da Taxa de
}

\section{Lucro}

\author{
The industrial-capital circuit and the dynamics of profit rate
}

Lucas Rodrigues $^{a}$

\begin{abstract}
Resumo: Este ensaio objetiva discutir a centralidade do circuito do capital-industrial para as investigações sobre a dinâmica de crise, em especial da queda na taxa de lucro, como desenvolvido por Marx. Apresenta três processos constitutivos desse circuito, que ao se desenvolverem estabelecem contradições com a lógica da valorização. O primeiro deles é a oposição entre capital e trabalho e a decorrente substituição do trabalho vivo pelo trabalho morto. O segundo é a forma concreta de existência do capital-industrial enquanto muitos capitais em concorrência entre si. O terceiro é a autonomização de certas funções exercidas pelo capital-industrial, que se expressam em circuitos próprios, mas subordinados ao primeiro. Todos esses fatores desencadeiam dinâmicas que se opõe à lógica de valorização, contribuindo para o declínio da taxa de lucro e o surgimento de crises.
\end{abstract}

Palavras-chave: Capital-industrial; Processo de Trabalho; Processo de Valorização; Concorrência; Autonomia Relativa

Classificação JEL: B51, D24, O33, P16

\begin{abstract}
This essay aims to discuss the centrality of the industrial-capital circuit for investigations on the dynamics of crisis, especially the fall in the rate of profit, as developed by Marx. It presents three constitutive processes of this circuit, which, when developed, establish contradictions with the logic of valorization. The first one is the opposition between capital and labor and the resulting replacement of live labor by dead labor. The second is the concrete form of existence of industrial-capital while many capitals compete with each other. The third is the autonomy of certain functions performed by industrial-capital, which are expressed in their own circuits, but subordinate to the first one. All these factors trigger a dynamics that oppose the logic of valuation, contributing to a decline in the rate of profit and the emergence of crises.
\end{abstract}

Keywords: Industrial-capital; Labor Process; Valorization Process; Competition; Relative Autonomy

JEL Classification: B51, D24, O33, P16

\footnotetext{
${ }^{\text {a }}$ Professor da Faculdade de Ciências Econômicas da Universidade Federal do Sul e Sudeste do Pará (FACE/Unifesspa). Email: lucas.rodrigues@ unifesspa.edu.br.
} 


\section{Introdução}

Os fazedores de política econômica que lutam para entender a enxurrada de pânicos financeiros, protestos e outros males que afligem o mundo fariam bem em estudar as obras de um economista morto há muito tempo: Karl Marx. Quanto mais cedo eles reconhecerem que estamos enfrentando uma crise sem precedentes do capitalismo, mais bem equipados eles estarão para administrar uma maneira de sair dela.

(George Magnus, 2011, ex-economista chefe do UBS Investment Bank, tradução própria) ${ }^{1}$

O desenvolvimento do modo de produção capitalista é caracterizado por um processo contraditório em que, por um lado, o capital impõe sua força totalizante e afirma sua lógica auto expansiva e, por outro, incorre em crises e rupturas que negam essa mesma lógica. Apesar de expansão e crise aparecerem como momentos separados no tempo, sua alternância revela a unidade em sua origem, na qual se sucedem como meio e fim uma da outra. Nesse sentido, os períodos de crescimento guardam a crise como latência, enquanto nessas últimas são gestadas as recuperações seguintes. Esses dois momentos não podem ser dissociados, uma vez que são a própria expressão da essência do capital enquanto valor que se valoriza e das formas como o faz dentro de uma dinâmica contínua de disputa.

A investigação de Marx e sua apresentação do capital revela o modo como o desenvolvimento desse, num processo de complexificação e generalização, também transforma a possibilidade de crise em necessidade. Todos os elementos que caracterizam e viabilizam a existência do capital como valor que se expande, também originam pressões para a ocorrência de rupturas e a interrupção dessa expansão. A expressão mais acabada desse processo contraditório é a tendência declinante da taxa de lucro. Essa tendência se impõe, para Marx, como lei dentro da dinâmica da acumulação.

Nesse artigo são apresentados os fatores constitutivos do circuito do capitalindustrial, que se relacionam com o movimento contraditório da acumulação. $\mathrm{O}$ argumento central é o de que o ponto de partida para os estudos de crise está contido na categoria do capital-industrial. Resumem-se em seu movimento tanto os fatores que atuam para uma trajetória declinante da lucratividade, quanto aqueles que colaboram para sua recuperação. Como elementos do primeiro estão a oposição entre capital e trabalho, a dinâmica da concorrência e a autonomização de certas funções inscritas nesse circuito. Pelo lado dos fatores que se opõe a essas forças estão a redução no valor do capital constante, o aumento da exploração da força de trabalho e, em momentos mais agudos de crise, a própria destruição de capital.

\footnotetext{
1 "Policy makers struggling to understand the barrage of financial panics, protests and other ills afflicting the world would do well to study the works of a long-dead economist: Karl Marx. The sooner they recognize we're facing a once-in-a-lifetime crisis of capitalism, the better equipped they will be to manage a way out of it".
} 
Na primeira seção desse trabalho é apresentada a definição de capital-industrial, feita por Marx. Desenvolve-se, de modo breve, a centralidade desse conceito como ponto de partida para os estudos do movimento da taxa de lucro e a tendência de crise, contida na dinâmica da acumulação.

Na segunda seção é apresentada a oposição entre capital e trabalho, fundamento da natureza específica do capitalismo enquanto relação social de produção. Essa oposição se reflete na alienação do trabalhador como sujeito do processo produtivo, e na efetivação do capital como seu regulador. Esse movimento, no entanto, estabelece uma relação contraditória dentro da própria lógica de valorização do capital. Por um lado, retira-se do trabalhador seu controle sobre o processo de trabalho, estabelecendo-se o ritmo e quantidade de sua atividade dentro do período contratado. Completa, portanto, a subordinação real do trabalho ao capital. Por outro lado, pressiona para uma redução da parte variável desse em relação a sua parte constante, estabelecendo um conflito com a própria fonte do valor.

$\mathrm{Na}$ terceira seção é discutida a contradição estabelecida pela forma concreta de existência do capital-industrial, enquanto inúmeros capitais individuais. Esses existem como unidades em constante disputa pela apropriação do mais-valor disponível. Embora no agregado possa haver uma tendência temporal de expansão do valor adiantado, essa é alcançada através do sucesso de algumas de suas partes e da destruição de outras. Cada fração existe, portanto, em oposição com o trabalho e em oposição com as demais. Nessa dinâmica, o aumento da produtividade torna-se elemento central para a sobrevivência individual. Esse elemento generaliza e torna imperativa a necessidade de racionalização e controle da produção. Seu resultado é que o capital investido em máquinas e equipamentos tende a crescer mais que o aplicado em força de trabalho. Essa é a própria expressão da disputa concorrencial que caracteriza as frações do capital-industrial.

Na quarta seção, discute-se a autonomização de certas funções contidas no circuito do capital-industrial e sua relação com a lucratividade. São expostas a formação do capital comercial e do capital portador de juros no modo de produção capitalista. O efeito desses sobre rentabilidade é, no entanto, mais indireto se comparados aos anteriores, influem em menor medida sobre a composição orgânica do capital adiantado e em maior sobre a distribuição do mais-valor existente. Por terem sua valorização subordinada ao circuito do capital industrial, mantém uma relação contraditória com a taxa de lucro. Quando mantidas dentro de determinadas proporções podem reduzir a massa total de valor adiantado e pressionar para cima a rentabilidade. No entanto, sua existência autônoma também permite que cresçam para além dos requisitos da produção, expandindo a massa de capital que disputa o mais-valor existente.

Com o desenvolvimento dos elementos apontados nesse trabalho, discute-se como o caráter cíclico da taxa de lucro e da acumulação de capital são expressão das características fundamentais do circuito do capital-industrial. O estudo dos ciclos exige, no entanto, a análise dos fatores que se contrapõe à dinâmica declinante da lucratividade, os quais fogem do escopo desse artigo. A partir dos argumentos aqui expostos, entende-se o 
capital-industrial como o ponto de partida para a compreensão dos fenômenos de crises do capital.

\section{O Circuito do Capital-industrial e a Dinâmica da Taxa de Lucro}

Marx desenvolve no livro III de O Capital a lei da queda tendencial da taxa de lucro, a qual se refere como a mais importante lei do modo de produção capitalista (Marx 2011, p. 497). Em sua exposição, demonstra como o processo de acumulação e de valorização do capital já contém sua própria negação, na forma de crises e rupturas (GRESPAN, 1994). Esses momentos tornam-se constitutivos do desenvolvimento do modo de produção capitalista, na medida em que se relacionam com os principais elementos que caracterizam sua dinâmica. Em primeiro lugar, com a centralidade do processo de valorização regulando o trabalho social; em segundo lugar, com o desenvolvimento contínuo das forças produtivas; e em terceiro lugar, com a substituição do trabalho vivo pelo trabalho morto. Esse processo vem acompanhado, no entanto, por forças que atuam em sentido contrário, e que também são originadas dentro da dinâmica de valorização e acumulação de capital (MARX, 1986). A interação entre esses fatores faz com que o movimento declinante da taxa de lucro não tenha uma forma de existência absoluta, mas opere apenas enquanto tendência.

O ponto de partida para se compreender a dinâmica da taxa de lucro é o processo de valorização do capital. O modo de produção capitalista é caracterizado pela organização da produção em que a finalidade não é o atendimento das necessidades da sociedade, mas sim a contínua expansão do valor. Se estabelece, uma contradição básica entre a produção de valores de uso e de valor. Tal contradição se dá, pois, apesar de o objetivo do processo produtivo ser a valorização de um capital inicialmente adiantado, essa só é possível pela realização de um processo de trabalho que se materializa na criação de valores de uso. Esses últimos são os suportes materias do valor, mas sua produção não é determinada pela necessidade social e sim pela necessidade do capital em valorizar-se. Para que esse processo se complete é preciso que as mercadorias (valores-de-uso) se realizem, isto é, que sejam absorvidas pela sociedade através dos atos separados de compra e venda. Tal separação já carrega a possibilidade de crises:

Possibilidade geral e abstrata da crise significa apenas a forma mais abstrata da crise, sem conteúdo, sem o impulso pertinente a esse conteúdo. Compra ·e venda podem separar-se. Constituem, portanto, crise em estado potencial e sua coincidência contínua sempre a ser, para a mercadoria, elemento crítico. Mas uma pode converter-se na outra com fluidez. Assim, a forma mais abstrata da crise (e por isso a possibilidade formal da crise) é a metamorfose da própria mercadoria, a qual, como movimento desenvolvido, contém a contradição - encerrada na unidade da mercadoria - entre valor de troca e valor de uso e ainda entre dinheiro e mercadoria. Mas o meio por que essa possibilidade de crise se torna a crise não se contém nessa própria forma; esta implica apenas em que existe a forma para uma crise. (MARX, 1980, p. 945). 
A passagem da crise de mera possibilidade para necessidade, dentro do modo de produção capitalista, é compreendida apenas quando se analisa o desenvolvimento do capital-industrial em sua totalidade. É dentro do circuito do capital-industrial que o processo de valorização se realiza, o qual, por sua vez, pode ser representado pela fórmula $D-M[F T ; M P] \ldots P \ldots M^{\prime}-D^{\prime}$. Nesse circuito, o capital assume suas diferentes formas de existência , isto é: capital-dinheiro, capital-produtivo e capital-mercadoria. Para que tal circuito seja contínuo, essas formas devem existir de maneira simultânea. No entanto, é apenas no processo de produção, ou seja, quando o capital se encontra como capitalprodutivo, que o valor é criado. Essa fase representa a unidade do processo de trabalho e de valorização, em que o valor contido nos meios de produção é conservado e transferido para as mercadorias finais e um novo valor é objetivado nessas. Apesar de todo capital, independentemente de sua forma, existir somente enquanto se expande, apenas uma parcela atua diretamente para a produção desse valor adicional.

A base do processo de valorização está, portanto, contida no circuito do capitalindustrial. Segundo Marx (1984, p. 43):

\begin{abstract}
O capital industrial é o único modo de existência do capital em que não só apropriação de mais-valia, ou, respectivamente, mais-produto, mas, ao mesmo tempo, também sua criação é função do capital. Condiciona, por isso, o caráter capitalista da produção; sua existência implica a contradição entre capitalistas e trabalhadores assalariados. Na medida em que se apodera da produção social, a técnica e a organização social do processo de trabalho são revolucionadas e com elas o tipo econômico-histórico da sociedade. As outras espécies de capital, que apareceram antes dele em meio a condições sociais de produção pretéritas ou decadentes, não só lhe são subordinadas e modificadas, de acordo com ele, no mecanismo de suas funções, mas só se movimentam ainda com base nele e, por isso, vivem e morrem, sustentam-se e caem. Capital-monetário e capital-mercadoria, na medida em que aparecem em suas funções de portadores de ramos próprios de negócios, ao lado do capital industrial são somente modos de existência, autonomizados e desenvolvidos unilateralmente pela divisão social do trabalho, das diferentes formas de função que, dentro da esfera da circulação, o capital industrial ora adota, ora abandona.
\end{abstract}

Dentro do circuito do capital-industrial estão contidos três elementos fundamentais da dinâmica capitalista que se relacionam com seu desenvolvimento contraditório expresso no movimento da taxa de lucro. Em primeiro lugar, a oposição entre capital e trabalho. Em segundo, o revolucionamento da "técnica e [d]a organização social do processo de trabalho" (MARX, 1984, p.43). Em terceiro, a subordinação das outras formas de capital e a autonomização de seus circuitos, os quais, no entanto, não contribuem diretamente para a criação de valor, apenas competindo por sua apropriação.

O capital-industrial enquanto condicionante do "caráter capitalista da produção" deve ser entendido como o ponto de partida para o estudo da dinâmica da acumulação e das crises. A forma como esses elementos se desenvolvem dentro do circuito do capital industrial e a sua relação com a lei da queda tendencial da taxa de lucro é fundamental para se afastar uma concepção mecânica dessa lei. Nas seções seguintes são apresentadas tais 
questões, expondo seu surgimento a partir do circuito do capital industrial e o modo como entram em contradição com ele. Pretende-se, com isso, discutir de que forma a valorização e acumulação de capital é indissociável de seu contrário: a queda tendencial na taxa de lucro e as crises.

\section{3. o Circuito do Capita-industrial e a oposição entre capital e trabalho}

O circuito do capital-industrial se inicia quando o capitalista transforma uma magnitude dada de dinheiro - seja próprio ou de terceiros - em capital através do ato de compra de meios de produção e contratação de força de trabalho. Esses dois elementos são reunidos no processo de produção para a criação de uma nova mercadoria, a qual será posteriormente vendida, voltando o capital à sua forma inicial. $\mathrm{O}$ sucesso de tal circuito dependerá de que a massa final retransformada em dinheiro seja maior do que aquela que deu início ao processo. Que o valor inicial dos meios de produção seja conservado na mercadoria final e um novo valor seja criado, suficiente para pagar a contratação de força de trabalho e gerar um ganho ao capitalista.

Essa ampliação do valor emerge do fato de que, mesmo que o capitalista contrate a força de trabalho pelo seu valor, ele a utiliza por um tempo superior ao necessário para criar esse mesmo valor. Marx separa, assim, a jornada de trabalho em duas partes. A primeira chama de tempo de trabalho necessário, na qual o trabalhador cria um valor igual àquele despendido para sua contratação. A segunda, refere-se ao tempo de trabalho excedente, em que uma quantidade adicional é criada e apropriada pelo capitalista (MARX, 1996). A contradição que se estabelece nessa relação é a de que apesar de o capitalista contratar a força de trabalho ele não contrata o trabalho em si, o qual permanece sob o domínio do trabalhador (BRYER, 2006). O resultado dessa contradição impõe a necessidade de desenvolvimento de inúmeras formas de organização e controle que visam garantir que a força de trabalho contratada por determinado período se transforme no máximo de trabalho efetivamente realizado. Historicamente, o desenvolvimento desses mecanismos tem dado origem a movimentos de resistência por parte dos trabalhadores e respostas por parte dos capitalistas (EDWARDS, 1978).

O processo de valorização exige a subordinação do trabalho ao capital, cujas bases estão na dependência do trabalhador para com o capital para produzir e criar sua própria reprodução, e na existência desse último como força autônoma dentro do processo de trabalho. Na medida em que a propriedade dos meios de produção se opõe ao produtor direto e que, portanto, a venda da força de trabalho torna-se uma necessidade para o trabalhador, o capital "subordina formalmente a força de trabalho criadora de valor e de 
mais-valia", reduzindo-a a momento de sua totalidade (GRESPAN, 1994, p. 14). A subsunção formal é, portanto, a base para o processo de criação do valor ${ }^{2}$.

No entanto, uma vez posta tal oposição desenvolvem-se mecanismos concretos de controle dentro do processo de produção, os quais evoluem para a mecanização e automação, que caracterizam a subsunção real do trabalho ao capital. Entendido dessa forma, a subsunção formal e real do trabalho não são dois momentos separados historicamente no aprofundamento do modo de produção capitalista. A primeira, como expressão da separação entre meios de produção e força de trabalho, é a base para a segunda, enquanto essa última é a forma concreta de manifestação da primeira.

Num primeiro momento, apesar de o trabalhador estar submetido ao capital e necessitar desse na realização da produção, ainda possui algum grau de domínio sobre o processo produtivo. Sua qualificação e especificidade o tornam um elemento de maior dificuldade de substituição, de modo que o ritmo e a forma de execução do trabalho permanecem sob seu controle. Nessas condições, o trabalho intelectual e manual ainda se encontram em alguma medida conectados na mesma pessoa do trabalhador.

A valorização do capital passa, assim, pela necessidade de separação dessas duas formas de trabalho e a restrição do poder do trabalhador dentro do processo produtivo. Desenvolvem-se sistemas de controle com a finalidade de direcionar as tarefas de trabalho, avaliar e mensurar sua execução e recompensar e disciplinar os trabalhadores (EDWARDS, 1978). Tais sistemas objetivam tanto o processo de trabalho quanto o de valorização.

No processo de trabalho, a principal forma para a subordinação real do trabalho ao capital é o emprego da maquinaria. Segundo Marx, é apenas com o desenvolvimento da grande indústria mecanizada que a subsunção real se completa. A maquinaria contém em si a separação do trabalho intelectual e do trabalho manual, além de determinar o ritmo e a forma da produção. Nesse sentido, "a máquina representa o trabalhador ideal; e o trabalhador efetivo meramente uma máquina imperfeita" (SHAIKH, 1978, p. 238). Para Edwards (1978) é o controle técnico que caracteriza a estrutura da grande corporação no final do séc. XIX. Essa forma de controle é um elemento fundamental para tais corporações, dado o afastamento entre os proprietários do capital e os trabalhadores, causado pela própria dimensão assumida por esses negócios.

No entanto, o controle técnico isolado também enfrenta limitações e resistências. Primeiramente, apesar de obter sucesso na imposição do ritmo de trabalho, ainda é insuficiente para as necessidades de avaliação e mensuração do trabalho, além do desenvolvimento de formas de recompensa e disciplina dos trabalhadores (Edwards, 1978,

\footnotetext{
${ }^{2}$ Segundo Grespan (1994, p. 275): "Precisamente neste sentido, por exemplo, deve ser compreendida a famosa passagem histórica da "cooperação" à "manufatura" e à "grande indústria", que poderia ser erroneamente interpretada como uma digressão narrativa da Revolução Industrial na Inglaterra. Trata-se, antes, da demonstração de como as condições efetivas da "subsunção formal" do trabalho ao capital têm em si mesmas a capacidade de se desenvolver em condições efetivas da "subsunção real", porque levam ao domínio do próprio processo de trabalho pelo capital e à sua "fetichização" enquanto fator de produção. Esta passagem, portanto, está inserida na lógica da conversão histórica em totalidade, em que o capital 'subordina a si todos elementos da sociedade"”.
} 
p. 117). Em segundo, dado que o controle técnico é caracterizado por uma ampla dependência entre as diferentes etapas do processo produtivo, a dificuldade de avaliar cada etapa separadamente e a possibilidade de resistência de poucos trabalhadores podem comprometer o processo produtivo como um todo. Por outro lado, a maquinaria ao fornecer a possibilidade de mensuração da capacidade produtiva auxilia no estabelecimento de metas e objetivos para a produção. Para Edwards (1978), a subordinação do trabalho ao capital avança ainda mais quando se estabelece o controle burocrático da empresa, caracterizado por uma estrutura hierárquica de comando, de determinação de funções e de objetivos.

Os mecanismos de controle e imposição do ritmo e da qualidade do trabalho excetuado se apresentam de inúmeras formas, caracterizando a subsunção real do trabalho ao capital. De acordo com o relatório sobre condições de trabalho da European Foundation for the Improvement of Living and Working Conditions (Eurofound) (BOISARD et al., 2003, p. 3) existem cinco maneiras principais utilizadas pelas empresas para determinar a intensidade e o controle do processo de trabalho.

a) determinantes automáticos, associados com a velocidade da máquina ou o movimento de um produto;

b) determinantes de objetivo, associados com metas numéricas de produção;

c) determinantes hierárquicos, associados com o controle direto dos chefes;

d) determinantes horizontais, associados com o trabalho executado por outros colegas de trabalho;

e) determinantes de demanda, associados com as solicitações diretas dos clientes.

O controle do processo de trabalho através da maquinaria e das formas de organização e comando é apenas uma das dimensões que competem para a subordinação real do trabalho ao capital. Como apontando acima, o processo de produção é composto pela unidade do processo de trabalho e do processo de valorização, no qual o segundo domina sobre o primeiro. Nesse aspecto, a subordinação real depende do desenvolvimento de métodos de controle da dinâmica de valorização. Para Bryer (2006), esses se dão através da contabilidade, a qual fornece os meios necessários para mensuração, avaliação, recompensa e disciplina do trabalho realizado. $\mathrm{O}$ controle do processo produtivo passa a se dar não apenas no chão de fábrica pela mecanização das atividades, mas especialmente através dos livros de contas e nas diretorias financeiras. O capital se transforma, através da gestão do processo de valorização pela contabilidade, numa força autônoma e irreconhecível para o trabalhador, o qual perde o domínio sobre sua atividade e seu resultado.

A contabilidade atua como mediadora na relação do capital individual consigo mesmo e assume na empresa a forma de contabilidade de custos. No entanto, o controle do processo de valorização também serve de ligação entre as várias frações que constituem o capital social total, assumindo a forma de contabilidade financeira (BRYER, 2006). É através desse mecanismo que essas distintas frações podem ser avaliadas, mensuradas e comparadas, possibilitando o movimento dos capitais entre as inúmeras empresas e setores. 
Sendo esse processo uma das manifestações da concorrência no modo de produção capitalista, em que se generaliza para os capitais individuais a necessidade de racionalização e controle da produção, fazendo com que essa forma específica assumida pela subordinação do trabalho se imponha para a totalidade da economia.

O desenvolvimento da maquinaria com a substituição do trabalho vivo por trabalho morto, somado aos mecanismos de gerenciamento da produção, são expressões da oposição entre capital e trabalho, em que o segundo está subordinado ao primeiro. Essa é a força principal de uma produção cada vez mais fundada na mecanização:

Segue-se daí que o impulso básico para a automação surge independentemente de movimentos em salários reais: do próprio fato de que o capital controla o processo de trabalho. É por esta razão que Marx pode derivar não apenas a transformação da manufatura pela maquinaria moderna, mas também o crescimento contínuo da mecanização do processo de trabalho [...]. (SHAIKH, 1978, p. 238, tradução própria) ${ }^{3}$.

A substituição de trabalho vivo por trabalho morto está na base do modo contraditório como se desenvolve o processo de valorização e acumulação do capital, o qual se revela na tendência declinante da taxa de lucro. Entender tal movimento exige um aprofundamento na análise da relação entre suas frações independentes, as quais existem em contínua concorrência e moldam a dinâmica da escolha técnica. São nessas disputas que as tendências acima expostas se tornam não apenas o modo de controle dos processos de trabalho e valorização, mas implicam na própria sobrevivência dos capitais particulares enquanto unidades independentes.

\section{Circuito do Capital-industrial, Concorrência e Mudança Técnica}

Do ponto de vista do capital-industrial total, sua capacidade de expansão encontra um limite na magnitude do mais-valor produzido durante cada período de rotação ${ }^{4}$. Em que "[o] limite superior da acumulação equilibrada é quando toda a mais-valia é reinvestida, em tal caso a taxa de crescimento do capital é igual à taxa de lucro"

\footnotetext{
3 "It follows from this that the basic drive towards automation arises independently of movements in real wages: out of the very fact that capital controls the labour process. It is for this reason that Marx can derive not only the transformation of manufacture by modern machinery but also the continued growth of mechanisation of the labour process $[\ldots] "$.

${ }^{4} \mathrm{~A}$ acumulação de capital na forma de investimento pode ser realizada por empréstimos, isto é, através de um adiantamento sobre a mais-valor a ser gerada. Essa possibilidade amplia os limites para a acumulação de capital, mas não rompe sua relação com o excedente de valor criado. Os empréstimos tomados num período deverão ser pagos posteriormente, o que significa uma subtração da mais-valor disponível ao capitalista num segundo momento. Como o crédito é um direito sobre uma produção futura, ao mesmo tempo em que amplia a capacidade de acumulação também gera um risco maior caso essa não seja realizada no nível esperado, e assim o pagamento dos empréstimos não se efetue da forma acordada.
} 
(SHAIKH, 2016, p. 227). No entanto, o capital-industrial tomado dessa forma se trata de uma abstração, pois o que de fato existe são as diferentes unidades independentes que o constituem. Apesar do mais-valor aparecer como limite da acumulação total, para suas partes individuais esse está em constante disputa. A concorrência é a forma que esse processo assume, seu funcionamento gera tanto movimentos de desequilíbrio quanto atua como mecanismo regulador (SHAIKH, 2016). Segundo Marx (2011, p. 338):

Conceitualmente, a concorrência nada mais é do que a natureza interna do capital, sua determinação essencial, que se manifesta e se realiza como ação recíproca dos vários capitais uns sobre os outros, a tendência interna como necessidade externa. O capital existe e só pode existir como muitos capitais e, consequentemente, a sua autodeterminação aparece como ação recíproca desses capitais uns sobre os outros. (Grifos no original)

O capital só pode existir enquanto se valoriza, ou seja, sua "autoconservação [..] é sua autovalorização" (MARX, 2011, p. 254). Essa constitui a "natureza interna do capital", a qual se torna imperativa para as frações que o compõe, através da concorrência. Sua forma de existência e expressão está no conflito entre as partes individualizadas. Para Shaikh (1990), todo o processo pode ser comparado ao de uma guerra: "O movimento do capital entre os setores determina o campo de batalha; o desenvolvimento e adoção de novas tecnologias corresponde ao desenvolvimento e adoção das armas de guerra; e a concorrência de uma empresa contra a outra corresponde à própria batalha" (SHAIKH, 1990, p. 84). Esses momentos, apesar de separados - escolha dos campos de batalha, preparação das armas e batalha - são expressão do impulso geral que impõe que para cada unidade de valor funcionar como capital, deva atrair e se apropriar de um novo valor ${ }^{5}$.

Em sua disputa pela valorização o capital procura inserir-se naqueles setores que oferecem os maiores retornos. Esse movimento pode ocorrer tanto pela entrada de novas empresas em determinadas indústrias quanto pela expansão daquelas já existentes. Essa forma intersetorial da concorrência origina uma tendência de equalização das taxas de lucro entre setores e atua na formação do que Marx (1986) chama de preços de produção. Por outro lado, a concorrência também estabelece que mercadorias iguais sejam vendidas por preços iguais no mercado, independente das diferenças com que são produzidas. Nesse aspecto, impõe que para as empresas sobreviverem e se expandirem devem produzir com menores custos que suas rivais. A concorrência assume assim sua forma intrasetorial, e resulta na formação de "uma hierarquia de rentabilidade dentro de cada indústria" (MALDONADO, 1989, p. 253).

Essas duas formas aparentes da dinâmica da concorrência estão em contínua interação e se retroalimentam, generalizando as tendências internas do processo de acumulação. A busca constante das empresas em reduzirem seus custos através da mudança

\footnotetext{
${ }^{5}$ Segundo Grespan (1994, p. 196): "Estes capitais singulares são todos capitais e, assim, perseguem idêntico objetivo de auto-valorização; e, já por isso, entram em conflito pelas oportunidades relativamente escassas de alcançarem seu objetivo comum. Este conflito, a concorrência, se estabelece pela oposição entre o que é comum a todo capital e a existência necessariamente determinada do capital enquanto capital singular, porque cada um destes deve realizar a finalidade geral como se fosse apenas sua, até em detrimento dos outros".
} 
técnica e aumento da produtividade faz com que se desviem das taxas de lucro vigentes. Esse movimento dá origem a um processo de absorção de capital por essas empresas ou setores, o que amplia e torna geral esses avanços, trazendo-as de volta para a situação média. As vantagens conseguidas pelas diferenciações intrasetoriais são, assim, limitadas pelos movimentos intersetoriais. $\mathrm{O}$ aprofundamento técnico, como elemento central na sobrevivência dos capitais individuais, torna-se característica geral do processo de acumulação.

Esse processo não significa que as composições orgânicas das diferentes indústrias apresentam qualquer tendência de equalização. Apenas que as melhores técnicas em cada setor, na medida em que se relacionam com taxas de lucro maiores, atraem novos capitais, os quais as replicam. Esse movimento implica em que apesar das diferentes composições orgânicas entre os setores, dentro de cada um se imponha uma tendência de aprofundamento técnico e expansão da parte constante do capital em relação a sua parte variável.

O motor do movimento intersetorial de concorrência é, assim, a formação de diferenciais de taxas de lucro, as quais atraem ou repelem novos capitais e novos investimentos. Segundo Shaikh (2016), esse processo de migração entre setores tem dois efeitos principais. O primeiro é o estabelecimento de capitais reguladores dentro de cada indústria. O segundo é uma tendência de equalização das taxas de lucro sobre os novos investimentos.

Os capitais reguladores são aqueles que determinam os preços de produção em cada setor, de modo que o preço de mercado tende a gravitar ao redor desses. Os primeiros são formados a partir dos custos de produção acrescidos do lucro médio correspondente à taxa geral de lucro. Dado que a lucratividade média não pode ser determinada por um capital isoladamente, a condição de regulação é atribuída à estrutura dos custos de produção. Segundo Shaikh (2016, p. 265), a luta da concorrência faz com que essa seja alcançada pelos capitais que detém as "melhores condições de produção geralmente reprodutíveis", em cada setor. A questão de reprodutibilidade é central, pois é essa taxa de lucro a qual se torna alvo de novos investimentos. Caso seja atraente, haverá um fluxo ${ }^{6}$ para essas empresas e setores:

[...] espera-se que novos capitais entrem no método de produção, que pode ser facilmente duplicado e, além disso, a taxa de lucro esperada é atraente o suficiente. O método de produção visado pelos novos participantes é geralmente o mais recente na indústria e não o mais antigo ou o mais lucrativo. Os métodos mais antigos de produção, ceteris paribus, terão uma taxa de lucro inferior à média, enquanto os métodos de produção mais lucrativos podem

\footnotetext{
${ }^{6}$ A entrada de novos capitais pode assumir a forma de novas empresas se estabelecendo nesses setores e/ou no uso de capital próprio ou de terceiros para investimento pelas empresas já estabelecidas. Em ambos os casos isso significa um aumento da capacidade produtiva, em especial utilizando as melhores condições reprodutíveis de produção. O efeito sobre a tendência à equalização das taxas de lucro com os demais setores é o mesmo, seja pela maior capacidade produtiva alcançada pelo aumento das empresas que operam nessa indústria, seja pelo aumento da capacidade das empresas já instaladas nela. Esse dinâmica é exposta de forma bastante clara por Sekine (1997, p. 158).
} 
não ser facilmente reproduzíveis ou sua reprodução está associada a certo grau de risco, que os novos entrantes podem não querer assumir. Assim, ao longo de "um ciclo de anos gordos e magros", ou seja, um ciclo completo de negócios, há uma tendência de a taxa de lucro se equalizar entre os capitais reguladores das indústrias. [...]. Na manufatura, as condições regulatórias de cada indústria podem não necessariamente coincidir com as condições médias, mas são determinadas pelo tipo de capital associado com os métodos de menor custo operando em condições geralmente reproduzíveis. (TSOULFIDIS; TSALIKI, 2011, p. 29).

Conjuntamente à formação de capitais reguladores em cada ramo, o processo intersetorial de concorrência resulta na equalização da rentabilidade entre os setores. Marx descreve essa tendência a partir do movimento gerado pelos diferenciais de taxas de lucro, os quais tendem a aumentar a oferta nos setores de maior lucratividade e diminuir nos de menor, regulando as taxas intersetoriais. Essa dinâmica se desenvolve, por sua vez, apenas como tendência. Segundo Semmler (1983, p. 42), isso se dá porque todo o movimento depende "das condições concretas da produção e circulação das mercadorias".

Por um lado, a busca constante dos capitais individuais por produzirem em melhores condições, e assim auferirem lucros maiores, impõe uma dinâmica de constante mudança. Conjuntamente, as formas fixas que o capital assume em seu circuito, estando essas impedidas de participar do processo de concorrência através da migração para outros setores, influem sobre a duração do processo. Esses dois elementos dão origem a um fenômeno empiricamente verificável de equalização das taxas de lucro incrementais entre indústrias, ou seja, da taxa de lucro sobre novos investimentos (SHAIKH, 2016; TSOULFIDIS, TSALIKI, 2011).

$\mathrm{O}$ fato de a taxa de lucro incremental apresentar uma tendência à equalização mais marcada que a taxa de lucro geral (SHAIKH, 2016) pode ser explicada por três fatores principais. O primeiro, devido a possibilidade de algumas empresas auferirem ganhos muito superiores aos de suas rivais, pelo uso de técnicas mais produtivas. Nesses casos, mesmo que o setor apresente uma lucratividade média baixa, reflexo da existência de empresas com técnicas obsoletas de produção, algumas firmas passam a apresentar altas taxas de retorno e atrair capitais. No começo, tais técnicas são de difícil acesso e as maiores rentabilidades persistem. No entanto, conforme alcançam a condição de replicação tornamse o alvo dos novos investimentos ${ }^{7}$. Mesmo quando a nova técnica fica amplamente disponível, a persistência de estruturas obsoletas pode gerar uma discrepância entre a taxa de lucro média do setor e a taxa de lucro incremental. Essa discrepância persistirá por mais ou menos tempo dependendo da forma da inovação, do volume de capital necessário, do risco envolvido em sua implantação e do tempo de maturação do investimento ${ }^{8}$.

\footnotetext{
${ }^{7}$ Segundo Geroski (1990), as taxas de lucro mais elevadas causadas por mudanças técnicas não geram, necessariamente, um aumento das empresas no setor. A possibilidade de entrada já é suficiente para levar à adoção dessas técnicas pelas empresas instaladas, ao aumento de capacidade e redução nos preços.

${ }^{8}$ Um exemplo de tal processo por ser encontrado na descrição feita por Landes (2005) sobre a substituição do ferro fundido pelo aço como material principal da siderurgia. As técnicas de fundição Bessemer e SimensMartin foram desenvolvidas ainda nos anos 1850, e possibilitavam a produção mais barata e em larga escala do aço. No entanto, a produção de ferro fundido superou a de aço até meados da década de 1880 na Inglaterra
} 
O segundo ponto relacionado com a equalização das taxas de lucro incrementais está ligado às formas concretas que o capital assume dentro do circuito do capital-industrial. Uma parcela desse permanece na forma de capital-dinheiro e encontra-se como saldos de caixa, fundos de reserva, de acumulação, de investimento, de precaução, de depreciação, etc. Simultaneamente, outra existe como capital-produtivo e aparece na forma de capitalfixo (edifícios, máquinas e equipamentos) e de capital-circulante (matérias-primas, produtos semiacabados e dispêndio com contratação de força de trabalho). Por fim, uma parte encontra-se constantemente como capital-mercadoria em estoque. Para o capitalista, sua taxa de lucro é calculada sobre todo o capital adiantado, independentemente de sua forma. No entanto, apenas o capital-dinheiro é capaz de migrar para qualquer setor. Tanto o capital fixo, circulante e os estoques de mercadorias acabadas têm de primeiro ser transformados em dinheiro, para só depois estarem aptos a movimentar-se entre as oportunidades alternativas de aplicação.

Somente uma parte do capital fica, assim, imediatamente passível de manobra pelo capitalista, e é essa parte a qual ele dispõe para buscar as melhores possibilidades de valorização. Esse fator torna o movimento das taxas gerais de lucro muito mais resistentes que o das taxas sobre novos investimentos. Apesar de o capitalista tentar manter a máxima valorização de todo seu capital, ele só o pode fazer com uma parcela desse. Como o investimento só é realizado caso sua lucratividade esperada seja vantajosa, é essa taxa de lucro incremental a qual guia o capital em sua forma mais líquida e serve de referência para seu movimento.

O terceiro fator, que influi na equalização da taxa de lucro incremental, diz respeito à própria dinâmica da inovação, a qual é distinta entre os setores e gera desequilíbrios mais ou menos acentuados entre eles. Dado que o tempo é elemento fundamental para a equalização das taxas de lucro, os constantes desequilíbrios causados pela acelerada mudança técnica podem gerar uma limitação para que a equalização da lucratividade geral seja empiricamente verificada. Por outro lado, essa dinâmica também acarreta uma alta volatilidade das taxas de lucro incrementais.

Tsoulfidis e Tsaliki (2011, p. 30) apontam para a questão de que as taxas de retorno de curto prazo condicionam os fluxos de investimento de maneira muito mais direta que as taxas de retorno sobre o tempo de vida total do investimento. As expectativas sobre as primeiras são muito mais passíveis de se concretizarem do que sobre as segundas, o que compete para as taxas de lucro incrementais servirem de referência no fluxo dos capitais.

Tanto o processo de formação de capitais reguladores, quanto de equalização das taxas de lucro atuam como forças que tornam a acumulação marcada pelo progresso técnico. Esses movimentos mais gerais se relacionam, no entanto, com a busca constante das empresas individuais por produzirem em melhores condições e auferirem um lucro maior que suas competidoras. São essas ações que criam os diferenciais de taxas de lucro,

e 1890 na França. Dentre os fatores apontados pelo autor para essa lenta substituição estão a enorme quantidade de capitais investidos em plantas com a técnica mais antiga de produção, os riscos e problemas atribuídos às fases iniciais das novas técnicas e a inércia e conservadorismo dos principais usuários de ferro fundido (ferrovias e indústria naval). 
os quais coordenam os fluxos dos capitais. A principal forma para se sobressaírem na luta competitiva é o aumento de produtividade e a redução dos custos de produção. Isso implica na racionalização e organização do processo produtivo, na diminuição da porosidade do trabalho e especialmente na mecanização.

Segundo Shaikh (1978), a concorrência intrasetorial também impõe um caminho para a escolha técnica, a qual resulta na maximização das margens de lucro e na queda agregada das taxas de lucro sobre o capital total investido. Esse resultado se dá pela forma ativa com que as empresas competem em relação à determinação de seus custos e preços de venda. A redução desses últimos é essencial para a expansão de sua capacidade de realização. Dado que o processo de acumulação resulta em um aumento da capacidade produtiva, e consequentemente na quantidade de valores de uso produzidos, as empresas são impelidas na luta da concorrência a expandirem sua participação de mercado. Essa necessidade faz com que a redução de custos seja elemento central para a expansão e sobrevivência das empresas. Para Shaikh (1978), essa se impõe, dentro da luta competitiva, de maneira ainda mais direta que a maximização dos lucros sobre o capital total investido.

A busca contínua das empresas de um mesmo setor por reduzirem seus custos não entra, no entanto, em conflito com a lógica da valorização. Uma empresa que melhora sua condição de produção tem uma vantagem momentânea em seus lucros, na medida em que não se vê obrigada a reduzir seus preços de venda. Esse fator se relaciona com a questão discutida acima dos capitais reguladores. No entanto, ao passo que as novas técnicas se tornam reprodutíveis e novos capitais entram em operação no setor, o aumento da oferta faz com que essa estrutura de produção se torne a reguladora.

Nesse sentido, o processo intrasetorial de concorrência é marcado por uma constante mudança na composição dos capitais que determinam os preços de produção e, portanto, na proporção em que se distribuem entre capital constante e capital variável. Para Shaikh (2016), esse movimento se revela no fato de que custos menores estão associados a uma maior intensidade de capital. Essa relação inversa entre custos e intensidade de capital também dá origem aos movimentos contraditórios de aumento das margens e diminuição das taxas de lucro.

Num primeiro momento, os menores custos e o aumento na massa de lucro auferida pela empresa impulsionam sua margem. No entanto, essa massa só é alcançada com um aumento na intensidade de capital, em geral na forma de capital fixo, o que faz reduzir a taxa de lucro sobre o total de capital adiantado.

Como apontado até aqui, o movimento de aumento da produtividade e mecanização da produção é intrínseco ao processo de acumulação e valorização do capital. A concorrência impõe que esse comportamento seja geral para os capitais individuais e para os diferentes setores. Essa dinâmica se manifesta, por sua vez, no aumento relativo da parte constante do capital sobre a parte variável, no crescimento do tamanho das empresas e num estreitamento dos limites para a própria valorização e acumulação do capital.

Esse comportamento está por trás da tendência declinante da taxa de lucro, ao determinar uma expansão menos acelerada do mais-valor em comparação com a magnitude total do capital avançado. No entanto, o circuito do capital-industrial dá origem a outro 
fenômeno que também concorre para tal tendência. Esse se relaciona com autonomização de determinadas funções contidas nesse circuito, as quais se fundam como capitais independentes e participam da competição pelo mais-valor disponível.

\section{O Circuito do Capital-industrial: Subordinação das Outras Formas do Capital e Autonomização de suas Funções}

O capital pode ser caracterizado, de forma bastante direta, como um valor que se valoriza (MARX, 1996). Nesse processo passa por uma série de etapas, em que ora assume uma forma para depois abandoná-la por outra. Apenas no circuito do capitalindustrial os momentos de produção e apropriação do valor estão explícitos. No entanto, nem todo valor percorre as mesmas etapas em sua trajetória de expansão. Alguns capitalistas desempenham meramente as funções de fazer circular o capital-mercadoria, portanto sem serem os responsáveis pelo processo de produção. Já outros, atuam no empréstimo capital-dinheiro, sem que esse se transforme para seu possuidor em capitalprodutivo e capital-mercadoria. No entanto, ambos os tipos de capitalistas operam dentro dessas atividades com o intuito de terem expandida a massa inicial de valores que adiantam.

Historicamente, os circuitos do capital-mercantil e do capital de empréstimo de dinheiro surgiram antes do capital-industrial. $\mathrm{O}$ circuito do primeiro compreende a transformação de uma magnitude de dinheiro em determinada mercadoria, a qual posteriormente reassume sua forma inicial, porém expandida: $\mathrm{D}-\mathrm{M}-\mathrm{D}$ '. O segundo é composto pelo adiantamento de certa magnitude de dinheiro e seu pagamento posterior acrescido de juros: D - D'. Ambos os circuitos permaneceram com o desenvolvimento do capital-industrial, entretanto, sofreram importantes modificações ao se tornarem formas subordinadas, porém relativamente autônomas dos momentos de circulação desse. Segundo Sekine (1997), o aprofundamento do modo de produção capitalista transformou o capital-mercantil em capital-comercial e o capital de empréstimo de dinheiro em capital portador de juros. Esse último constituindo a base do capital-bancário e do sistema de crédito.

A diferença fundamental apresentada pelo autor (SEKINE, 1997) está relacionada à forma de valorização que tanto o capital-mercantil como o capital de empréstimo de dinheiro apresentavam antes de sua subordinação ao capital-industrial. Os ganhos provenientes das atividades de compra e venda tinham um caráter de lucro por alienação, caracterizando-se pela arbitragem e especulação. Nesse aspecto, a valorização do capitalmercantil dependia que operações de compra e venda estivessem separadas espacialmente (arbitragem) e/ou temporalmente (especulação). Os ganhos do capital de empréstimo de dinheiro, por sua vez, provinham da cobrança de juros pelos seus possuidores, em caráter de usura. A finalidade dos empréstimos estava menos relacionada 
com o aumento da produção e mais vinculada ao financiamento do capital-mercantil, às guerras e ao consumo da aristocracia. Isso se traduzia em juros usurários e não raro no pagamento desses através da apropriação da riqueza previamente acumulada, e não dos acréscimos nas rendas geradas.

Por sua vez, a existência de uma massa de valor na forma de dinheiro apta a ser emprestada estava diretamente ligada a uma classe específica possuidora de riqueza nessa forma. Tanto o capital-mercantil quanto o capital de empréstimo de dinheiro apresentavam circuitos independentes entre si, existindo como unidades separadas, e sua valorização dependia de alguma forma de lucro por alienação. Ou seja, da apropriação das rendas de porções da sociedade pelos proto-capitalistas que operavam nessas atividades, de modo que, no agregado, o ganho de uma parte significava a perda de outra ${ }^{9}$. Por mais que tais atividades pudessem gerar um lucro dentro dos circuitos em que operavam, esses resultavam em uma redistribuição das rendas existentes (SHAIKH, 2016, p. 209).

O desenvolvimento do capital-industrial promoveu a transformação dessas formas de capital, sem o desaparecimento de suas funções. Esses deixaram de ter uma natureza independente e passaram a existir de modo subordinado ao circuito do capital-industrial, porém com relativa autonomia. Constituíram, assim, momentos separados da unidade desse circuito mais amplo ${ }^{10}$.

Como discutido anteriormente, o capital-industrial assume, em seu processo de valorização, as formas de capital-dinheiro, capital-produtivo e capital-mercadoria. Todas essas formas devem existir simultaneamente, em diferentes proporções, para que esse circuito seja contínuo e ininterrupto. No entanto, apenas enquanto capital-produtivo atua diretamente para a criação de novos valores. Permanecendo como dinheiro ou mercadorias sua manutenção e gerenciamento incorrem em custos. Para o capitalista industrial, a diminuição do tempo e da quantidade em que seu capital se encontra nessas outras formas é determinante para a magnitude dos lucros. A aceleração da circulação e

\footnotetext{
${ }^{9}$ O domínio do capital-mercantil num período em que o capital-industrial ainda era bastante incipiente caracterizou a política comercial do tipo empobrecer-seu-vizinho (beggar-your-neighbour, em inglês) do período mercantilista (MADDISON, 2001). O lucro por alienação como fonte da valorização dos capitais investidos no comércio e nas finanças impunha um resultado nas relações mercantis entre os países típico de um jogo de soma zero.

${ }^{10}$ Segundo Marx (2011, p. 349): "Razão pela qual o crédito, em qualquer forma desenvolvida, não aparece em nenhum modo de produção anterior. Em estados anteriores também havia tomar e conceder empréstimo, e a usura é até mesmo a mais antiga das formas antediluvianas do capital. Todavia, emprestar e tomar emprestado não constitui o crédito, da mesma maneira que trabalhar não constitui o trabalho industrial ou o trabalho assalariado livre. Como relação de produção essencial e desenvolvida, o crédito só aparece historicamente na circulação fundada sobre o capital ou sobre o trabalho assalariado. (O próprio dinheiro é uma forma de abolir a desigualdade do tempo requerido nos diversos ramos de produção, visto que tal desigualdade obstrui a circulação.) Não obstante a própria usura, em sua forma aburguesada, adaptada ao capital, seja uma forma de crédito, em sua forma pré-burguesa é antes expressão da falta de crédito.
} 
dos dispêndios com o gerenciamento dos fluxos de pagamentos e recebimentos tornamse elementos de vantagens competitivas.

Segundo Marx, é possível que esses momentos da circulação do capital-industrial sejam realizados por capitais separados, dando origem às duas formas do capitalcomercial: capital de comércio de mercadorias e capital de comércio de dinheiro. Essas representam apenas a existência autônoma dos processos de circulação já existentes no circuito do capital-industrial. Se anteriormente não geravam um novo valor, também agora não o fazem, obtendo sua remuneração através da apropriação de parte do maisvalor criado no processo de produção.

Diferentemente do que ocorria com o capital-mercantil, o lucro nessas esferas não tem origem na alienação ou na transferência de rendas, mas no próprio processo produtivo. Mantendo-se em proporções adequadas, o efeito esperado dessa relativa autonomização dos processos de circulação é a redução na magnitude total do capital adiantado, caso todo o processo ficasse a cargo do capitalista industrial (MARX, 1986, p.9). Nesse sentido, tem um efeito positivo sobre a taxa geral de lucro.

O capital de empréstimo de dinheiro também sofre uma mutação conforme o capital-industrial torna-se o modo dominante de existência do capital. Esse assume a forma desenvolvida de capital portador de juros, o qual acrescida das funções do capital de comércio de dinheiro, funda o capital bancário e todo o sistema de crédito. Duas são as mudanças principais introduzidas por essa nova relação. A primeira delas diz respeito à origem dos juros que valorizam os capitais investido nesse circuito. A segunda se relaciona à própria origem desses capitais.

Segundo Marx, a capacidade de o dinheiro funcionar como capital e obter lucro adiciona a ele um novo valor de uso, e nesse sentido transforma-o numa mercadoria particular:

\begin{abstract}
Dinheiro - considerado aqui como expressão autônoma de uma soma de valor, exista ela de fato em dinheiro ou em mercadorias - pode na base da produção capitalista ser transformado em capital e, em virtude dessa transformação, passar de um valor dado para um valor que se valoriza a si mesmo, que se multiplica. Produz lucro, isto é, capacita o capitalista a extrair dos trabalhadores determinado quantum de trabalho não-pago, mais-produto e mais-valia, e apropriar-se dele. Assim adquire, além do valor de uso que possui como dinheiro, um valor de uso adicional, a saber, o de funcionar como capital. Seu valor de uso consiste aqui justamente no lucro que, uma vez transformado em capital, produz. Nessa qualidade de capital possível, de meio para a produção de lucro, torna-se mercadoria, mas uma mercadoria sui generis. Ou, o que dá no mesmo, o capital enquanto capital se torna mercadoria. (MARX, 1986, 256).
\end{abstract}

Essa possibilidade do dinheiro em funcionar como capital, e, portanto, ser transacionado como mercadoria, está na base dos juros no modo de produção capitalista. $\mathrm{O}$ processo contínuo de produção e as relações que se estabelecem entre produtores e compradores, conjuntamente com os refluxos mais ou menos regulares de certa magnitude de dinheiro nos circuitos do capital favorecem a utilização do crédito. O produtor vende 
suas mercadorias ao comerciante não por um recebimento imediato, mas por um título que corresponde a uma promessa futura de pagamento (forma de crédito comercial). Por sua vez, pode descontar tal título em um banco pagando uma taxa de desconto (forma de crédito bancário $)^{11}$. Para que tais operações sejam vantajosas aos capitalistas envolvidos, é necessária a realização de um lucro após os pagamentos dos juros e descontos.

Como a origem dos juros é a capacidade do dinheiro - "considerado aqui como expressão autônoma de uma soma de valor, exista ela de fato em dinheiro ou em mercadorias" - funcionar como capital, e esse só opera como tal no processo de produção através da criação de mais-valor, os juros se tornam parte do novo valor criado. Diferente do que ocorria com o capital de empréstimo de dinheiro, em que sua valorização resultava de alguma transferência do circuito da renda ou da riqueza acumulada, a expansão do capital portador de juros depende da apropriação do mais-valor gerado no circuito do capital-industrial. No entanto, por adquirir uma existência relativamente autônoma, qualquer magnitude de dinheiro emprestada obtém o direito a um acréscimo futuro na forma de juros. Esse é cobrado mesmo que o valor cedido nunca funcione como capital, ou seja, mesmo que jamais opere dentro do circuito do capital-industrial

A segunda diferença fundamental que o capital portador de juros mantém em relação ao de empréstimo de dinheiro diz respeito à origem dos fundos que operam nesse circuito. Esses não estão mais ligados a uma classe específica possuidora de riqueza na forma de dinheiro ou metais preciosos, mas se originam principalmente dos fundos ociosos criados no próprio circuito do capital-industrial ${ }^{12}$. Tais fundos são necessários à continuidade do processo produtivo, ou mesmo se formam de maneira automática pela depreciação do capital fixo. Em outros casos, podem se acumular de maneira indesejada pelas empresas, principalmente em um excesso nos superávits de caixa, os quais não encontram aplicação imediata.

\footnotetext{
${ }^{11}$ Sobre a forma como crédito comercial e bancário se relacionam ver Germer (1994).
}

12 Segundo Sekine (1997, p. 97): "À medida que o capitalismo se desenvolve, no entanto, a classe de emprestadores de dinheiro profissionais (ou seja, aqueles que sempre emprestam seu dinheiro a juro e nunca o investem na circulação ou produção de mercadorias com fins lucrativos) tende a desaparecer. A concessão e tomada de empréstimos de fundos que são temporariamente inconversíveis em capital, no entanto, tornam-se uma operação capitalista subsidiária, conhecida como "finanças" ou capital de empréstimo, praticada por todos os capitalistas, industriais e comerciais. Como será explicado abaixo, os capitalistas de empréstimo são bastante diferentes dos emprestadores de dinheiro. Representando apenas um aspecto particular das funções dos capitalistas industriais e comerciais, eles não constituem por si próprios uma classe separada" (As capitalism develops, however, the class of professional money-lenders (i.e. those who always lend their money for an interest and never invest it in the circulation or production of commodities for a profit) tends to disappear. The lending and borrowing of funds which are temporarily inconvertible into capital, however, become a subsidiary capitalist operation, known as "finance" or loan-capital, engaged in by all capitalists, industrial and commercial. As will be explained below, loan-capitalists are quite unlike money-lenders. Representing only a particular aspect of the functions of industrial and commercial capitalists, they do not by themselves constitute a separate class). 
Com o desenvolvimento do sistema de crédito e bancário a tendência é que esses fundos migrem do circuito do capital-industrial ou comercial para o circuito do capital portador de juros. Mesmo o crédito comercial só é possível na medida em que existam fundos ociosos ou a serem criados, uma vez que isso permite ao produtor adiar o recebimento sem que necessite interromper a produção (SEKINE, 1997, p. 134-142). Caso esses recursos permanecessem no circuito do capital-industrial, imporiam um fardo aos capitalistas que os carregam, já que apesar de não gerarem nenhum lucro continuam contanto como capital a ser valorizado e, portanto, impactam negativamente sobre a lucratividade:

Este fardo pode ser reduzido apenas se o dinheiro ocioso que é formado por um capital (por exemplo, como fundos de depreciação) pode ser utilizado como meio de pagamento por outro capital, de modo a acelerar a conversão de mercadorias em dinheiro. Pois, nesse caso, não apenas a proporção do capital-dinheiro ocioso para o ativo diminui na sociedade, mas a proporção do capital-circulação para o capital produtivo também pode, em consequência, ser socialmente reduzida. Isso permite que uma proporção maior do capital social total se engaje diretamente na produção de mais-valor. (SEKINE, 1997, p. 97, tradução própria) ${ }^{13}$.

O efeito mais imediato do desenvolvimento do capital portador de juros e sua expansão através do sistema bancário e financeiro é uma dinamização da acumulação de capital. Essa expansão permite o aumento da produção sem que haja uma acumulação prévia pelo capitalista e a reunião de vários capitais dispersos para realizar empreendimentos de maior magnitude. No entanto, a existência autônoma desse circuito origina dois fatores que podem ter um efeito disruptivo sobre a lucratividade geral e consequentemente sobre a dinâmica econômica.

O primeiro deles se relaciona ao fato de que, dado que o circuito do capital portador de juros se torna o destino de todo dinheiro ocioso, uma vez que determinada magnitude de valor se transforme em capital - operando em qualquer circuito - essa não deixa de funcionar como tal. Ou seja, o circuito do capital portador de juros, e das finanças em geral, torna-se o destino daquela parcela de valor que deixaria de ser valorizada, transformandose em consumo ou sendo entesourada ${ }^{14}$. Dessa forma, retarda a diminuição do montante de

\footnotetext{
13 "This burden can be reduced only if idle money that is formed by one capital (e.g. as depreciation funds) can be utilized as means of payment by another capital, so as to expedite the conversion of commodities into money. For, in that case, not only is the proportion of idle to active money-capital diminished in society, but the proportion of circulation-capital to productive capital too can, in consequence, be socially lowered. That enables a greater proportion of the aggregate social capital to engage itself directly in the production of surplus value".
}

${ }^{14}$ Segundo Freeman (2012, p. 180, tradução própria): “[...] qualquer pessoa com uma quantia de dinheiro tem uma escolha e pode investi-la na produção ou em ativos que rendam juros. À medida que a taxa de lucro cai, as oportunidades de investimento produtivo lucrativo também caem: a compra de ativos que rendem juros tornase a alternativa mais lucrativa para um número crescente de capitalistas. [...] Esse dinheiro ficou ocioso; em épocas anteriores, ele congelaria como estoques de metais preciosos, mas, com o desenvolvimento dos mercados de crédito, ele congela como estoques de títulos negociáveis, para os quais cria uma demanda. Mas 
valor que disputa o mais-valor disponível e limita, mesmo que momentaneamente, a queima de capital, pressionando para baixo a taxa de lucro.

$\mathrm{O}$ segundo fato, o qual se relaciona ao primeiro, diz respeito às pressões que os capitais ociosos que migram para o circuito do capital portador de juros exercem sobre a criação de formas para sua valorização. Segundo Cipolla e Pinto (2010), essas pressões se traduzem no desenvolvimento de uma série de ativos financeiros e modalidades de empréstimos com diferentes prazos e vínculos. Dado que a possibilidade de gerar juros se torna uma propriedade de todo capital emprestado, independentemente do modo como é utilizado, sua aplicação não mantém uma relação necessária com o aumento e os requisitos do capital-produtivo. Tem-se, portanto, a existência de uma massa sempre crescente de valor que não deixa de buscar sua valorização e, conjuntamente, a criação de instrumentos de crédito que significam um direito sobre o mais-valor a ser produzido, sem necessariamente contribuir para sua produção.

A relação do capital-industrial com o capital portador de juros, e a autonomia desse último, também podem dar origem a movimentos especulativos e rupturas. Primeiramente, a tendência ao aumento do crédito surge da própria expansão do capital-industrial. Seja devido às dimensões dos empreendimentos se tornarem maiores que a magnitude dos capitais isolados, seja pelo risco implicado em tais investimentos, os quais desincentivam os capitalistas a inverter todo seu capital nele, recorrendo ao de terceiros. Ainda, a expansão dos mercados e a aceleração das trocas favorece também o crescimento do crédito comercial.

Todas essas operações geram, por sua vez, instrumentos de crédito na forma de títulos, ações e promessas de pagamentos. Esses títulos compõem a "maior parte do capital bancário" (MARX, 1986, p. 13) ${ }^{15}$, e podem, por sua vez, ser negociados. O mercado secundário desses papéis transforma-os no que Marx chama de capital fictício, os quais apresentam uma dinâmica própria de precificação e valorização, ligada às variações na taxa

\begin{abstract}
onde há demanda, surge uma oferta. E o crédito pode ser criado sem nenhum dos limites impostos pela produção material, como comprovou a engenhosidade dos banqueiros de investimento nas últimas décadas. Ao lado do capital produtivo atado em ativos fixos, uma pilha tóxica de instrumentos geradores de renda se ergue" ([...] anyone with a sum of money has a choice and can invest it either in production, or in such interest-bearing assets. As the rate of profit falls, opportunities for profitable productive investment likewise fall: the purchase of interest bearing assets becomes the most profitable alternative for growing numbers of capitalists. [...] Such money has become idle; in earlier times it would congeal as hoards of precious metals but, with the development of credit markets, it congeals as hoards of negotiable securities, for which it creates a demand. But where there is a demand, a supply emerges. And credit can be created without any of the limits imposed by material production, as the ingenuity of the investment bankers in recent decades has proven. Beside the productive capital tied up in fixed assets, a toxic slag-heap of income-bearing instruments rears up). Dessa forma o dinheiro ocioso assume a forma de capital portador de juros e não mais de entesouramento. Continua, assim, disputando a mais-valor existente, sem colaborar diretamente para sua formação. Pressiona, dessa forma, para a redução na taxa de lucro, seja por aumentar o denominador desse cálculo, seja por se apropriar da mais-valor e reduzir seu numerador.
\end{abstract}

${ }^{15}$ Aqui capital bancário compreende todo setor financeiro, bancário e não-bancário. 
de juros e a demanda por eles. Segundo Freeman (2012), na medida em que se desenvolve esse mercado secundário, os títulos se tornam mais uma opção de investimento para os capitalistas. As finanças passam a desviar não apenas as receitas provenientes dos demais circuitos, mas o próprio capital:

\begin{abstract}
Em primeiro lugar, não é o setor financeiro que é o problema. É a finança, da qual todos os capitalistas se valem como substituto do investimento produtivo. Em segundo lugar, a finança não desvia receita: desvia capital. Em última análise, os instrumentos financeiros são apenas uma forma de dinheiro ocioso: uma porção cada vez maior do capital social não está envolvida na atividade produtiva, mas se acumula como um tesouro de títulos parasitas. (FREEMAN, 2012, p. 181, tradução própria) ${ }^{16}$.
\end{abstract}

A atração de capital proporcionada pela expansão do capital fictício, e seu movimento autônomo de valorização, possibilitam que a criação de crédito e títulos se descole das necessidades do capital-industrial - essa é a expressão principal da autonomia relativa. Apesar de inúmeros instrumentos financeiros terem sua origem das demandas deste último, ao se tornarem opções lucrativas de investimento passam a ser criados meramente pelas perspectivas de ganho que carregam, inaugurando assim processos especulativos e a formação de bolhas financeiras. Marx (1986, p. 24) descreve esse processo nos "negócios de mercadorias realizados somente com a finalidade de fabricar letras", mas historicamente inúmeros ativos se tornam objeto de especulação e bolhas (ações, moedas, hipotecas, etc.). Segundo Freeman (2012), o fato de as finanças se tornarem uma opção de investimento para os capitalistas faz com que os valores nela invertidos também sejam incluídos nos cálculos da taxa geral de lucro ${ }^{17}$. Essa atração dos capitais ociosos se acentua ainda mais conforme diminui tendencialmente a lucratividade dos investimentos produtivos.

Na medida em que os circuitos do capital-industrial e das finanças se relacionam, num processo contínuo de entrada e saída de capital entre eles, o rendimento aparece ao capitalista como um atributo de todo seu capital, independente do circuito em que opera. No entanto, o processo contínuo de valorização de qualquer capital depende da criação constante de mais-valor, e a desproporção entre essa e o capital em suas distintas formas é apenas resolvida ao custo de crises. Como observado acima, esses circuitos relativamente autônomos se originam da separação dos momentos de circulação do capital-industrial.

\footnotetext{
16 "First, it is not the financial sector which is the problem. It is finance, of which all capitalists avail themselves as a substitute for productive investment. Second, finance does not divert revenue: it diverts capital. In the last analysis, financial instruments are merely a form of idle money: an ever-growing portion of social capital is not engaged in productive activity but accumulates as a hoard of parasitic titles".
}

\footnotetext{
${ }^{17}$ Para uma exposição sobre o cálculo da taxa de lucro na presença de capital-comercial e financeiro ver Norfield (2012) e Freeman (2012).
} 
Essa autonomização significa que esses momentos não formam nem uma unidade estrita nem tampouco uma separação completa ${ }^{18}$. A mesma lógica apresentada por Marx sobre a possibilidade de crises dada a autonomia relativa que os momentos de compra e venda adquirem entre si, pode ser aplicada na relação entre o circuito do capital-industrial e os demais circuitos que surgem da autonomização de suas funções. Segundo Grespan (1994), são as crises que restauram violentamente a lógica e a vinculação interna desses momentos relativamente autônomos:

De fato, o texto diz que "se elas fossem somente separadas... então não seria possível... nenhuma crise", ou seja, sua unidade seria impossível e esta separação simples seria uma necessidade absoluta, por excluir a possibilidade de efetivação de seu oposto; a venda e a compra necessariamente não teriam relação uma com a outra e não haveria o aspecto "violento", "destrutivo", que caracteriza a crise. Por outro lado, "se elas fossem apen as uma... então não seria possível nenhuma separação violenta, o que novamente é a crise", isto é, a separação seria agora impossível e a unidade, enquanto identidade imediata, excluiria a possibilidade de seu oposto, configurando também sua necessidade absoluta. (GRESPAN, 1994, p.72).

O desenvolvimento do circuito do capital-industrial, o qual tem como objetivo a expansão contínua do valor, é constituído e origina uma série de processos contraditórios os quais tendem a levar o sistema econômico à crise. Marx apresenta, ao longo dos três volumes de O Capital, o modo como essas passam da esfera da possibilidade para a esfera da necessidade, dentro do modo de produção capitalista (GRESPAN, 1994). No entanto, tal necessidade também existe de maneira relativa, tornando a acumulação marcada pela sucessão de ciclos. Esse processo detém, assim, uma natureza contínua de afirmação e negação. Em seu movimento, origina simultaneamente inúmeros fatores que se opõem a uma trajetória absoluta de ruptura. Esses assumem formas concretas de existência, as quais podem ser observadas nas oscilações e tendências da dinâmica econômica. Analisá-los é fundamental para a compreensão das possibilidades e limites do próprio movimento contínuo de acumulação.

\footnotetext{
${ }^{18}$ Segundo Marx (1986, p. 228): “Apesar de sua autonomização, o movimento do capital comercial é apenas o movimento do capital industrial dentro da esfera da circulação. Mas, por força de sua autonomização, ele se movimenta, dentro de certos limites, independentemente das barreiras do processo de reprodução e, por isso, o impele para além de suas próprias barreiras. A dependência interna e a autonomia externa impelem o capital comercial até um ponto em que a conexão interna é restabelecida à força, mediante uma crise”. A mesma afirmação pode ser extrapolada para a expansão do capital nos circuitos das finanças.
} 


\section{Conclusão}

O circuito do capital-industrial é o ponto de partida para a compreensão da dinâmica econômica na sociedade capitalista. Nele estão contidas as principais tendências do movimento da acumulação, das expansões de formas específicas do capital e das situações de crises. Se originam nesse circuito os impulsos ao desenvolvimento das forças produtivas, das disputas intracapitalistas e da relação entre capital e trabalho. A tendência declinante da taxa de lucro é expressão aparente das contradições que se originam no movimento do capital-industrial, de modo que os estudos desse movimento devem partir de tal conceito. Nesse circuito o capital se apresenta em todas as suas diferentes formas e em cada uma delas desempenha as suas funções específicas e essenciais para o processo de valorização.

Um dos pontos centrais neste artigo foi evidenciar que a acumulação de capital é composta também pelo seu oposto, elementos de sua negação, os quais se originam do próprio capital-industrial. As forças que levam à expansão do trabalho morto em relação ao trabalho vivo não podem ser dissociadas desse circuito, nem a acumulação ocorrer sem elas. Essas são característica constitutivas da dinâmica da acumulação, que fazem Marx tratar a tendência de declínio da taxa de lucro como lei no modo de produção capitalista e não meramente como questão conjuntural. Entende-se, nesse sentido, que fenômenos contemporâneos como a expansão das finanças devem ser compreendidos a partir do circuito do capital-industrial e da relação que mantém com ele. A impossibilidade de viver de modo separado desse circuito e o impulso que o capitalindustrial dá tanto para seu crescimento quanto para sua autonomização, estão na base das rupturas que aparecem apenas na superfície como fenômenos exclusivos do circuito do capital portador de juros. As crises que neles se originam restauram a unidade dessa autonomia relativa entre os demais circuitos do capital e daquele que permitiu sua origem.

É importante destacar que a análise teórica sobre a centralidade do capitalindustrial no movimento declinante da taxa de lucro e nas dinâmicas das crises em geral, também decorre em implicações para estudos empíricos. Em grande medida, utiliza-se no denominador do cálculo da lucratividade o estoque de capital fixo, o que representa apenas parcela limitada do capital-industrial. Como argumentado, a continuidade desse circuito depende que o capital exista, simultaneamente, em suas diferentes formas. Essas devem ser incluídas de alguma maneira nesses estudos, especialmente com as transformações recentes na composição dos ativos das empresas. Por exemplo, o não reinvestimento do lucro em aumento da capacidade produtiva e o destino dessa parcela do capital para investimentos financeiros, modifica o modo como o capital-industrial se distribui entre suas formas de capital-mercadoria, capital-produtivo e capital-dinheiro, porém não reduz o seu montante. Essas questões vêm sendo trabalhadas dentro do marxismo e, em grande medida, a dificuldade de mensuração dos ciclos de cada uma das formas do capital-industrial restringem as possibilidades de inclusão dessas nos cálculos de lucratividade. Reforça-se, por fim, a necessidade no desenvolvimento de estudos e proposições teóricas e empíricas nesse sentido. 


\section{Referências (fonte Tahoma, 11. Em negrito)}

BOISARD, Pierre et al. Time and work: work intensity. Ireland: EUROFOUND, 2003.

BRYER, Rob A. Accounting and control of the labour process. Critical Perspectives on Accounting, [s. 1.], v. 17, n. 5, p. 551-598, 2006. DOI:

https://doi.org/10.1016/i.cpa.2003.06.010.

CIPOLLA, Francisco Paulo; PINTO, Geane Carolina Rodrigues. Crítica das teorias da financeirização. Revista Sociedade Brasileira de Economia Política, [s. 1.], n. 27, p. 6$28,2010$.

EDWARDS, Richard C. The social relations of production at the point of production. Critical Sociology, [s. 1.], v. 8, n. 42403, p. 109-125, 1978. DOI: https://doi.org/10.1177/089692057800800213

FREEMAN, Alan. The profit rate in the presence of financial markets: A necessary correction. Journal of Australian Political Economy, [s. 1.], v. 70, n. 70, p. 167-192, 2012.

GERMER, Claus M. O Sistema de crédito e o capital fictício em Marx. Ensaios FEE, [s. 1.], v. 15, n. 1, p. 179-201, 1994. Disponível em:

https://revistas.dee.spgg.rs.gov.br/index.php/ensaios/article/view/1696

GEROSKI, P. 1990. Modelling Persistent Profitability. In: MUELLER, D. (Ed.). The Dynamics of Company Profits. Cambridge, U.K.: Cambridge University Press.

GRESPAN, Jorge Luís da Silva. A dinâmica da crise: Um estudo sobre o conceito de crise na crítica da economia política de Marx. 1994. 318 f. Tese (Doutorado) - Curso de Filosofia, Universidade Estadual de Campinas, Campinas, 1994.

LANDES, David S. Prometeu desacorrentado. São Paulo: Campus, 2005.

MADDISON, ANGUS. The World Economy: A Millenial Perspective. Paris: OECD, 2001.

MAGNUS, George. Give Karl Marx a Chance to Save the World Economy. 2011.

Disponível em: <https://www.bloomberg.com/view/articles/2011-08-29/give-marx-achance-to-save-the-world-economy-commentary-by-george-magnus $>$. Acesso em: 07 jul. 2017.

MALDONADO FILHO, Eduardo Augusto de Lima. Concorrência e diferenciais intersetoriais de rentabilidade: uma análise da indústria brasileira-1973/85. Ensaios FEE, [s. 1.], v. 10, n. 2, p. 251-265, 1989. Disponível em: https://revistas.dee.spgg.rs.gov.br/index.php/ensaios/article/view/1378. 
MARQUETTI, A. Do rising real wages increase the rate of labor-saving technical change? some econometric evidence. Metroeconomia, Malden, v. 55, n. 4, p.432-441, out. 2004. DOI: https://doi.org/10.1111/j.1467-999X.2004.00201.x

MARX, Karl. Grundrisse. São Paulo: Boitempo, 2011.

MARX, Karl. O Capital livro II. São Paulo: Abril, 1984.

MARX, Karl. O Capital: Livro I. São Paulo: Nova Cultural, 1996.

MARX, Karl. O Capital: Livro III Vol IV. São Paulo: Nova Cultural, 1986.

MARX, Karl. Teorias da mais-valia. São Paulo: DIFEL, 1980.

MEYER, Stephen. The degradation of work revisted: workers and technology in the American auto industry, 1900-2000. 2004. Disponível em: < http://www.autolife.umd.umich.edu/Labor/L Overview/L Overview1.htm>.

NORFIELD, T. Finance, the Rate of Profit and Imperialism. Paper for MPE2 session, WAPE/AHE/IIPPE conference, Paris, 5-7 July. 2012. Disponível em:

$<$ https://thenextrecession.files.wordpress.com/2014/11/norfieldtonyfinance_the_rate_of_profit_and_-imperialism.doc.>

SEKINE, Thomas T. An Outline of the Dialectic of Capital. London: MACMILLAN PRESS, 1997. a. v. 1.

SEKINE, Thomas T. An Outline of the Dialectic of Capital. London: MACMILLAN PRESS, 1997. b. v. 2.

SEMMLER, Willi. Competition, Monopoly, and Differentils of Profit Rates: Theoretical Considerations and Empirical Evidence. Review of Radical Political Economics, [s. 1.], v. 15, n. 4, p. 92-99, 1983. DOI: https://doi.org/10.1177/048661348201300405

SHAIKH, Anwar. Capitalism: Competition, Conflict, Crises. New York: Oxford University Press, 2016.

SHAIKH, Anwar. Political economy and capitalism: notes on Dobb's theory of crisis. Cambridge Journal of Economics, [s. 1.], v. 2, n. 2, p. 233-251, 1978. DOI: https://doi.org/10.1093/oxfordjournals.cje.a035388

SHAIKH, Anwar. Valor, acumulacion y crisis: ensayos de economía política. Bogotá: Tercer Mundo Editores, 1990

TSOULFIDIS, Lefteris; TSALIKI, Persefoni. Classical competition and regulating capital: theory and empirical evidence: Munich Personal RePEc Archive Classical. Munich, 2011. 